\title{
Clinical Efficacy of a Mouth-Exercising Device Adjunct to Local Ointment, Intra-Lesional Injections and Surgical Treatment for Oral Submucous Fibrosis: a Randomized Controlled Trial
}

\author{
Pravinkumar Patil ${ }^{*}$, Vinay Hazarey ${ }^{2}$, Rekha Chaudhari², Smita Nimbalkar- \\ Patil $^{3}$
}

\begin{abstract}
Background: Oral physiotherapy or mouth exercise is considered to be an adjunct but mandatory treatment modality for oral submucous fibrosis (OSMF). This study planned to evaluate the clinical efficacy of a newly designed mouth exercising device (MED) in OSMF patients receiving local ointment, intra-lesional drugs and surgical treatment. Materials and Methods: A total of 231 OSMF patients were selected and treated with basic regime including topical corticosteroids, oral antioxidants and the icecream-stick exercise regime and allotted randomly to two equal groups $A$ and B. Group-A patients were additionally given MED. Subgroups A1 and B1 patients with an inter-incisal distance (IID) $20-35 \mathrm{~mm}$ were not given any additional therapy; subgroup A2 and B2 patients (IID 20-35mm) were treated additionally with intra-lesional injections. Subgroups A3 and B3 with IID $<20 \mathrm{~mm}$ were managed surgically. IID was measured at baseline and at 6 months recall. The change in IID measurements was calculated and statistically analyzed using 2-way ANOVA and Tukeys multiple post hoc analysis. Results: Average improvement in IID after six months of recall visits was observed to be $8.4 \mathrm{~mm}$ in subgroup-A1 (n-53) compared to $5.5 \mathrm{~mm}$ in B1(n-50) (p<0.01). The IID improvement in subgroup-A2 was found to be $9.3 \mathrm{~mm}(\mathrm{n}-46)$ compared to $5.1 \mathrm{~mm}$ in $\mathrm{B} 2(\mathrm{n}-48)(\mathrm{p}<0.01)$. In the surgery group, mouth opening improvement was observed to be $9.6 \mathrm{~mm}$ in subgroup A3 (n-18) compared to $4.8 \mathrm{~mm}$ for $\mathrm{B3}(\mathrm{n}-16)(\mathrm{p}<0.01)$. Conclusions: Use of the MED appears to be effective for increasing oral opening in OMSF patients in conjunction with local, injection and/or surgical treatment.
\end{abstract}

Keywords: Medical devices - oral precancer - oral submucous fibrosis - oral physiotherapy

Asian Pac J Cancer Prev, 17 (3), 1255-1259

\section{Introduction}

Oral submucous fibrosis (OSMF) is a chronic oral mucosal condition that affects predominantly Indians and other Asians (Pindborg and Sirasat, 1966). The disease is slowly spreading all over the world including Europe and America due to expansion of the South Asian immigrant population (Aziz, 2010; Farrand et al., 2001). The hallmark of the disease is progressive subepithelial fibrosis of the oral soft tissues resulting in restricted mouth opening and burning sensation (Sinor et al., 1990; van Wyk et al., 1990). The aetiology of the disease is mainly due to chewing of betel quid/areca nut (Sinor et al., 1990). The treatment of the OSMF is focused to cessation of the betel nut habit, restoring the mandibular range of motion, oral cancer surveillance and improving mouth opening. Local and surgical treatments have been advocated depending upon the severity of the mouth opening. Treatment based upon a presumed inflammatory basis supports use of steroids, interferon gamma, or anti-inflammatory placental extracts, dietary supplementation and injection of derivative enzymes to facilitate fibrous tissue removal (Sinor et al., 1990; Angadi and Rao, 2010). Mouth exercising is the well-established supporting treatment to improve opening and also to prevent postsurgical relapse (Lai et al., 1995; Le, Gornitsky et al., 1996; Heller, Wei et al., 2005; Cox and Zoellner, 2009; Angadi and Rao, 2010; Patil and Patil, 2012). Cox and Zoellner, (2009) tested the hypothesis that physiotherapy alone can modify tissue remodeling in OSMF to increase oral opening. Various oral physiotherapy devices were described in the literature (Le, Gornitsky et al., 1996; Farrand et al., 2001; Heller, Wei et al., 2005; Cox and Zoellner, 2009) Most of them were tooth-borne, where opening force can be applied with the help of the devices or stents placed between the maxillary and mandibular arches or teeth. Mouth-opening devices for this purpose are fixed to the teeth to keep the dental arches apart (Le, Gornitsky et al., 1996; Cox and Zoellner, 2009). Partially or totally edentulous arches, decayed teeth, or periodontitis, do not allow for the use of such devices,

${ }^{1}$ Division of Clinical Dentistry, School of Dentistry, International Medical University, ${ }^{3}$ Department of Orthodontics, Faculty of Dentistry, MAHSA University, Kuala Lumpur, Malaysia, ${ }^{2}$ Department of Oral Pathology, Government Dental College and Hospital, Nagpur, India*For correspondence: pravinandsmita@yahoo.co.in 
and often patients suffering from severe trismus present with these conditions. A non-tooth-borne mouth-opening device applying force to two intraoral screws placed in the vestibule of the maxillary and mandibular bones is described in such situations (Heller, Wei et al., 2005). Patient noncompliance prevents surgical intervention for placement of the screws and limits the use of such devices. A new mouth exercising device (MED) has been designed which is non-tooth-borne, handy and easy to use by the patients (Patil and Patil, 2012). The MED causes local squeezing and stretching of the mucosa. This exercise effect causes increase in elasticity of the mucosal tissues and ultimately result into increase in mouth opening. The MED is non-tooth-borne device that is simple to fabricate and easy to use by the patients. The MED can also be used in patients with poor dental conditions and can allow rehabilitation to start immediately after surgical release of the fibrous bands. Long-term clinical efficacy of oral physiotherapy devices in association with local ointments or intra-lesional injections or surgical treatment is still unclear. Purpose of this paper is to evaluate and compare the clinical efficacy of the MED exercise among the OSMF patients in association with local ointment application, intra-lesional drugs administration and surgical treatment.

\section{Materials and Methods}

\section{Trial design}

The study was designed as a randomized controlled clinical trial. The trial and the clinical protocol were approved by the Institutional Ethical Committee of the Government Dental College and Hospital, Nagpur. Clinical trial is registered at www.ctri.nic.in. with the trial registry number is CTRI/2013/05/003609.

\section{Participants}

The OSMF diagnosed patients were selected randomly from the out patient department of the Government Dental College and Hospital, Nagpur on the basis of set clinical criteria between the age-group of 18-40 yrs. The patients with interincisal distance (IID) between 5-30mm who agreed to volunteer for the study, ready for giving informed consent and willing to return for the follow-ups were selected. All patients were given written informed consent to enroll in the study and to undergo the treatment

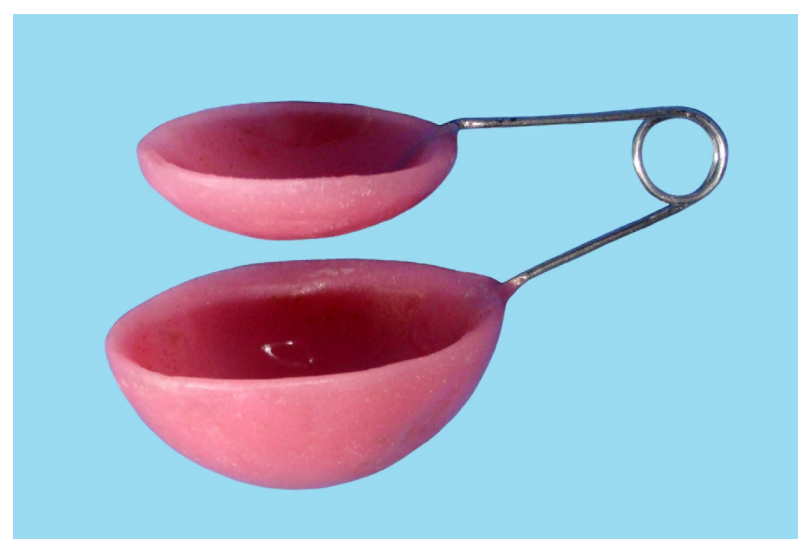

Figure 1. Mouth Exercising Device intervention. Patients with any history of systemic disease with hepatic, respiratory, renal, cardiac or hematological disease, with active treatment for OSMF in last 1 month, with presence of any malignancy and HIV positive status, with persistent or severe infection in last 3 months were excluded from the study. The patient allocation, intervention and dropout is indicated in a CONSORT 2010 flowchart (Table 1).

\section{Intervention}

Each patient was counseled for complete discontinuation of the habit. Every patient was treated with a local application of the Clobetasol Propionate, oral antioxidant and Ice-cream-stick exercise regime irrespective of the group for intention to treat (Table 2). This basic treatment modality for all registered patients is a suggestion by the co-author $\mathrm{VH}$ with his long clinical experience and knowledge in the field. The ointment was applied with an applicator swab to affected mucosa three times a day. Antioxidant preparation was given in the capsule form once a day for 6 months. All patients were allotted randomly to two groups: Group A (MED) and B (Control) each with three subgroups namely A1, A2 A3 (MED users) and B1, B2, B3 (non MED users). SubGroup A1 and B1: IID: 20-35 mm, to be treated without any additional therapy; SubGroup A2, B2: IID: 20-35 mm, to be treated with intra-lesional injections (Depomedrol); Subgroup A3, B3: IID $<20 \mathrm{~mm}$ to be treated surgically with buccal-fatpad augmentation. Fabrication and use of the MED: The fabrication and use of the MED was first described by Patil and Patil (2012) (Figure 1). The MED can be used by positioning the smaller plate intraorally and the bigger plate extraorally as shown in figure 2 . The check mucosa can be squeezed repeatedly by changing the position of the MED all over the affected region. The patients were encouraged to exercise for 20 minutes (10 minutes on each side) with the help of MED 3 times daily unless discomfort or tissue injury occurs. The patients were scheduled for recall visits every month for 6 months (Patil and Patil, 2012). Once a patient had given informed consent, randomization was done at the Department of Prosthodontics in our institute. Fabrication of the MED was designed by Patil and Patil (2012) using resin-plates and a metal-wire-coil.

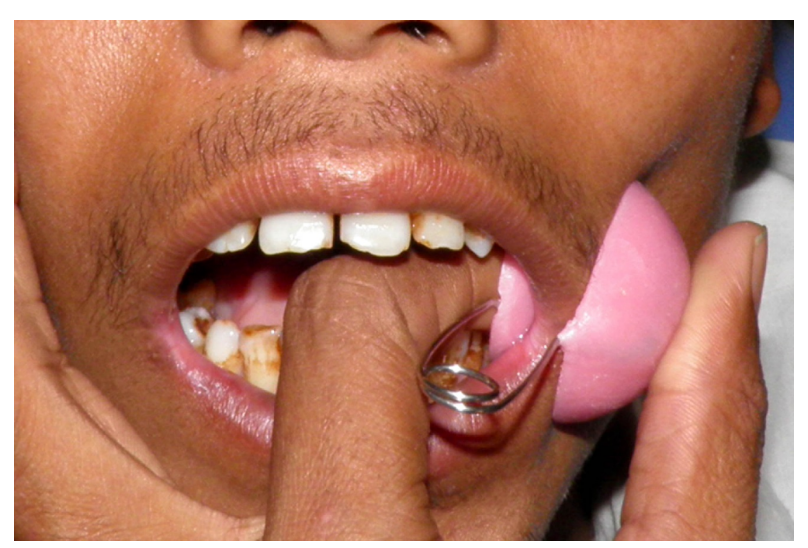

Figure 2. Patient Using Device 
Table 1. Patient Dropout Flowchart

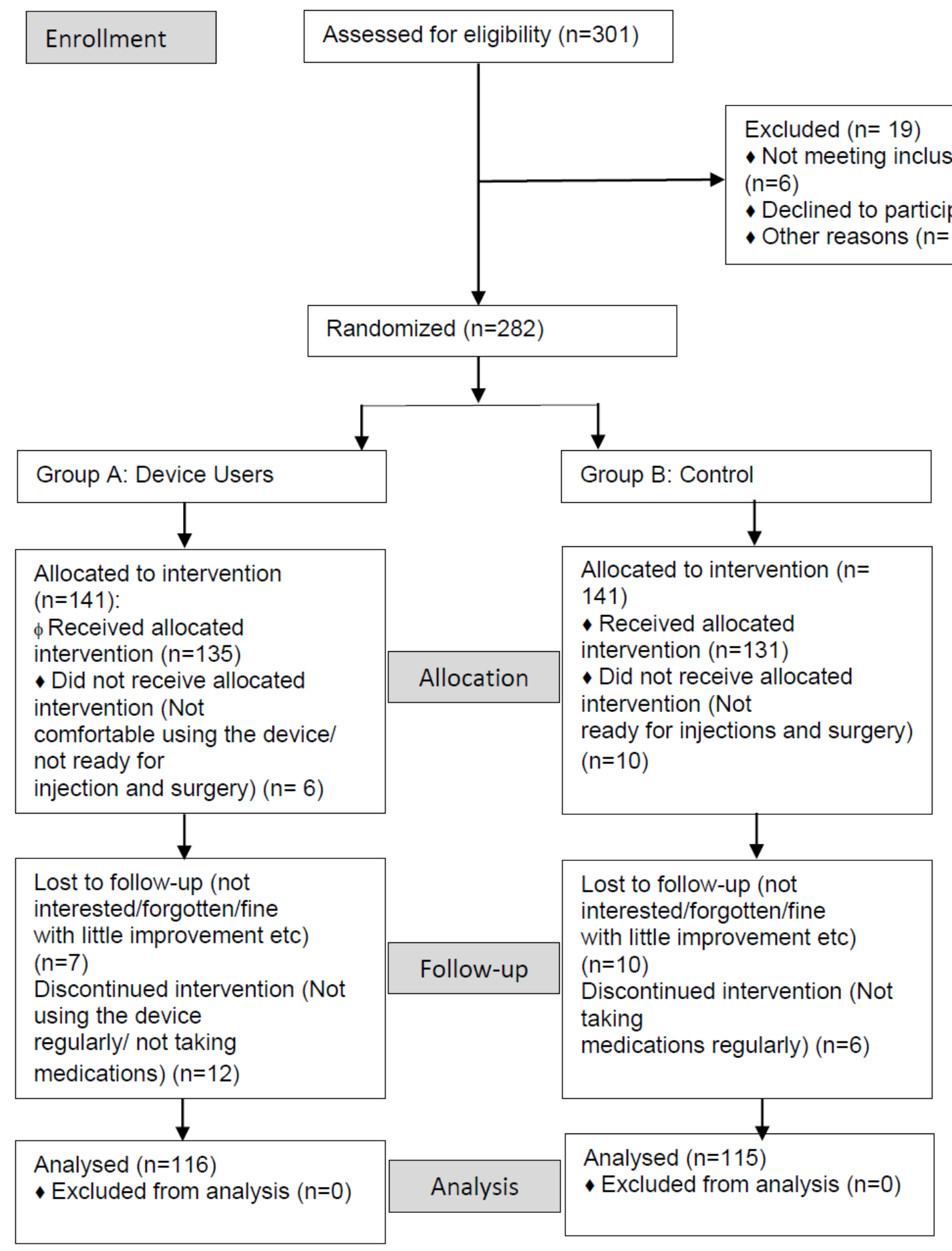

Outcome and data analysis

Patients were assessed for IID evaluation before treatment and after 1,3 and 6 months Loss to follow-up was defined as those who failed to attend the latest study visit. During each follow-up visit inter-incisal distance (IID) was measured on maximum opening with the help of digital calliper (in $\mathrm{mm}$ ) for evaluating the improvement in mouth opening. The Change in the IID was calculated by the difference in the measurements at baseline and 6 months recall visit IID readings. For surgery group patients, the baseline measurements were taken after healing followed by 6 months recall reading thereafter. The data was collected and analyzed statistically using 2-way ANOVA and Tukeys multiple post hoc analysis. For the first part of the quantitative analysis, only initial and six monthly IID were used. The Pair wise comparison of main groups Group A and B and Subgroups A1, A2 A3 (MED users) and B1, B2, B3 (non MED users) with improvement in mouth opening scores in $\mathrm{mm}$ after 6 months visits were analyzed using by Tukeys multiple post hoc procedures. All statistical analyses were based on the intention-to-treat principle. The significance level was set at $\alpha=0.05$.

\section{Results}


Table 2. Sample Distribution According to the Type of Treatment Allocated

\begin{tabular}{|c|c|c|}
\hline Treatment & \multicolumn{2}{|c|}{ Additional treatment given in separate subgroups } \\
\hline \multirow{6}{*}{$\begin{array}{l}\text { Intervened to all Clobetasol propionate } \\
(0.05 \%) 2 \text { times/day } \\
+ \\
\text { Oral Antioxidants } 1 \\
\text { time/day } \\
+ \\
\text { Ice-cream stick regime } 1 \text { time/day } \\
(\mathrm{n}=231)\end{array}$} & $\begin{array}{l}\text { Subgroup A1 }(\mathrm{n}=35) \\
\text { Local (No additional treatment) }\end{array}$ & \multirow{3}{*}{$\begin{array}{l}\text { Group A } \\
\text { Device } \\
(\mathrm{n}=116)\end{array}$} \\
\hline & $\begin{array}{l}\text { Subgroup A2 ( } \mathrm{n}=30) \\
\text { Injections ( } 1 \mathrm{ml} \text { Depomedrol+1 } \mathrm{ml} \text { Local Anesthesia: Once } \\
\text { a week) }\end{array}$ & \\
\hline & $\begin{array}{l}\text { Subgroup A3 }(\mathrm{n}=10) \\
\text { Band removal Surgery }\end{array}$ & \\
\hline & $\begin{array}{l}\text { Subgroup B1 }(\mathrm{n}=35) \\
\text { Local (No additional treatment) }\end{array}$ & \\
\hline & $\begin{array}{l}\text { Subgroup B2 }(\mathrm{n}=30) \\
\text { Injections ( } 1 \mathrm{ml} \text { Depomedrol+1 ml Local Anesthesia: Once } \\
\text { a week) }\end{array}$ & $\begin{array}{l}\text { Group B } \\
\text { No Device } \\
(\mathrm{n}=115)\end{array}$ \\
\hline & $\begin{array}{l}\text { Subgroup B3 }(\mathrm{n}=10) \\
\text { Band removal Surgery }\end{array}$ & \\
\hline
\end{tabular}

Table 3. Improvement in Mouth Opening Scores between Device Users (group A) and Non-device Users (Group B) and Within the Sub-groups after 6 months by Two-way ANOVA

\begin{tabular}{lccccc}
\hline Groups & $\begin{array}{c}\text { Degrees of } \\
\text { freedom }\end{array}$ & $\begin{array}{c}\text { Sum of } \\
\text { squares }\end{array}$ & $\begin{array}{c}\text { Mean sum } \\
\text { of squares }\end{array}$ & F-value & P-value \\
\hline Main effects & 1 & 697.7797 & 697.7797 & 297.2542 & $0.0000^{*}$ \\
$\begin{array}{l}\text { Device users against non-device users } \\
\text { Within all subgroups }\end{array}$ & 2 & 3.63 & 1.815 & 0.7732 & 0.4628 \\
$\begin{array}{l}\text { 2-way interactions } \\
\text { Main groups against sub-groups }\end{array}$ & 2 & 30.7823 & 15.3911 & 6.5566 & $0.0017^{*}$ \\
Error & 225 & 528.1689 & 2.3474 & & \\
\hline Total & 230 & 1260.3609 & & & \\
\hline
\end{tabular}

*p $<0.05$ Note that gray shaded blocks are indicating the statistically significant values

Table 4. Pair wise comparison of improvement in mouth opening scores between device users and non-device users and within the sub groups after 6 months by Tukeys multiple post hoc analysis

\begin{tabular}{|c|c|c|c|c|c|c|c|}
\hline & \multicolumn{3}{|c|}{ Device users (Group A) } & \multicolumn{3}{|c|}{ Non Device users (Group B) } \\
\hline \multicolumn{2}{|c|}{ Device-users Vs Non-Device users } & \multirow{2}{*}{$\frac{\mathrm{A} 1}{8.4038}$} & \multirow{2}{*}{$\frac{\mathrm{A} 2}{9.263}$} & A3 & B1 & \multirow{2}{*}{$\frac{\text { B2 }}{5.1438}$} & \multirow{2}{*}{$\frac{\mathrm{B} 3}{4.8313}$} \\
\hline \multicolumn{2}{|l|}{ Mean } & & & 9.6167 & 5.51 & & \\
\hline \multicolumn{2}{|l|}{$\begin{array}{l}\text { Mean } \\
\text { SD }\end{array}$} & 1.7174 & 1.6329 & 1.3853 & 1.4376 & 1.4057 & 1.3671 \\
\hline \multirow[t]{3}{*}{ Device Users } & A1 & \multicolumn{6}{|l|}{1} \\
\hline & $\mathrm{A} 2$ & 0.0602 & \multicolumn{5}{|l|}{1} \\
\hline & A3 & $0.0431 *$ & 0.962 & \multicolumn{4}{|l|}{1} \\
\hline \multirow[t]{3}{*}{ Non Device Users } & $\mathrm{B} 1$ & $0.00001^{*}$ & $0.00001 *$ & $0.00001 *$ & \multicolumn{3}{|l|}{1} \\
\hline & $\mathrm{B} 2$ & $0.00001 *$ & $0.00001 *$ & $0.00001 *$ & 0.8452 & \multicolumn{2}{|l|}{1} \\
\hline & B3 & $0.00001 *$ & $0.00001^{*}$ & $0.00001 *$ & 0.6367 & 0.9812 & 1 \\
\hline
\end{tabular}

After six months of recall visits, average improvement in IID in the subgroup A1 (n-53) was $8.4 \mathrm{~mm}$ and in subgroup B1 ( $\mathrm{n}-50)$ was $5.5 \mathrm{~mm}(\mathrm{p}<0.01)$ (Table 3 and 4$)$. In patients treated with intra-lesional injections, average improvement in IID for subgroup A2 (n-46) was $9.3 \mathrm{~mm}$ and for subgroup B2 (n-48) was $5.1 \mathrm{~mm}(\mathrm{p}<0.01)$ (Table 3 and 4). In surgery group, the improvement was measured in comparison with the immediate post-surgical opening, and the average improvement after six month recall was found to be $9.6 \mathrm{~mm}$ for subgroup A3(n-18) and $4.8 \mathrm{~mm}$ for subgroup B3(n-16) $(\mathrm{p}<0.01)$ (Table 3 and 4).

\section{Discussion}

Local squeezing and stretching of the cheek mucosa can be achieved with the help of MED (Patil and Patil, 2012). Improvements in oral openings of the patients using the MED with local ointment, injection and surgery were found to be $8.4 \mathrm{~mm}, 9.3 \mathrm{~mm}$ and $9.6 \mathrm{~mm}$ respectively in the patients and $5.5 \mathrm{~mm}, 5.1 \mathrm{~mm}$ and $4.8 \mathrm{~mm}$ in the patients not using the device. Although exact mode of action of the MED cannot be explained in particular with OSMF, the biokinetics can be explained and partially correlated with the therapeutic ultrasound. The effect of therapeutic ultrasound on improvement of mouth opening was studied and concluded that it was one of the effective treatment modality for the OSMF. The physiotherapeutic effect of pulsed ultrasound causes loosening of adherent fibrous tissue, probably due to the separation of collagen fibers from each other and softening of the cement substance, 
thus leading to increased elasticity (Patil and Patil, 2012; Arora and Deshpande, 2010; Bierman, 1954; Hashibe et al., 2002). This phenomenon is well described in mature scar management (Bierman, 1954; Hashibe et al., 2002). The MED (due to massage effect) causes separation of the collagen fibers and may increase the subcutaneous matrix areas leading to improvement in blood circulation. Van Beekvelt et al (2001) studied the blood flow and muscle oxygen uptake at the onset and end of moderate and heavy dynamic forearm exercise. The results revealed that forearm blood flow and muscle oxygen uptake increased in moderate exercise while decreased during heavy exercise (Van Beekvelt, 2001). The exercise regimen for the MED was chosen based on the judgment that the patient should not perform heavy exercise, and limits the moderate exercise to 10 minutes on each side at a time with repetition of three to five times a day. The duration and frequency required for the exercise can be lessened, subject to the patient's normal comfort level.

The first step before starting any treatment regimen for OSMF is to reinforce to the patient the need to stop the habit of taking areca nut or tobacco in any form like gutkha, mava, kharra, etc. Occurrence of tissue remodeling due to oral physiotherapy with regular use of the MED should be studied at the microscopic level. According to previous literature patient's cooperation is the primary requirement for success in the physiotherapy treatment of OSMF. Evaluating the clinical efficacy of the new MED will suggest further scope for more definitive physiotherapeutic treatment modalities in OSMF. The Source of Funding: Authors thank the 'Lady Tata Memorial Trust, Mumbai, India' for completely funding this clinical trial under the 'Institutional Research Grant program' (Dated 14 December 2011).

\section{Acknowledgment}

The authors thank staff and postgraduate students from the Department of Oral Pathology, Oral Surgery and Prosthodontics for their help. Authors also thank Dr. Pankaj Bodade, MDS, Oral Medicine Diagnosis and Radiology, for his help in developing the research plan.

\section{References}

Angadi PV, Rao S (2010). Management of oral submucous fibrosis: an overview. Oral Maxillofac Surg, 14, 133-42.

Arora PK, Deshpande M (2010). Effect of ultrasound and jaw opening exercises in cases of oral submucous fibrosis. Indian J Physiother Occup Ther, 4, 45-7.

Aziz SR (2010). Coming to America: betel nut and oral submucous fibrosis. J Am Dent Assoc, 141, 423-8.

Bierman W (1954). Ultrasound in the treatment of scars. Arch Phys Med Rehabil, 35, 209-14.

Cox S, Zoellner H (2009). Physiotherapeutic treatment improves oral opening in oral submucous fibrosis. J Oral Pathol Med, 38, 220-6.

Farrand P, Rowe RM, Johnston A, et al (2001). Prevalence, age of onset and demographic relationships of different areca nut habits amongst children in Tower Hamlets, London. $\mathrm{Br}$ Dent J, 190, 150-4.

Hashibe M, Sankarnarayanan R, Thomas G, et al (2002). Body mass index, tobacco chewing, alcohol drinking and risk of oral sub mucous fibrosis in Kerala, India. Cancer Causes Control, 13, 55-64.

Heller F, Wei FC, Chang YM, et al (2005). A non-tooth-borne mouth-opening device for postoperative rehabilitation after surgical release of trismus. Plast Reconstr Surg, 116, 1856-9.

Lai DR, Chen HR, Lin LM, et al (1995). Clinical evaluation of different treatment methods for oral submucous fibrosis. A 10-year experience with 150 cases. J Oral Pathol Med, 24, 402-6.

Le PV, Gornitsky M, Domanowski G (1996). Oral stent as treatment adjunct for oral submucous fibrosis. Oral Surg Oral Med Oral Pathol Oral Radiol Endod, 81, 148-50.

Patil PG, Patil SP (2012). Novel mouth-exercising device for oral submucous fibrosis. J Prosthodont, 21, 556-60.

Pindborg JJ, Sirasat SM (1966). Oral submucous fibrosis. Oral Surg Oral Med Oral Pathol, 22, 746-79.

Sinor PN, Gupta PC, Murti PR (1990). A case control study of oral submucous fibrosis with special reference to the etiologic role of areca nut. J Oral Pathol Med, 19, 94-98.

Van Beekvelt MC, Shoemaker JK, Tschakovsky ME, et al (2001). Blood flow and muscle oxygen uptake at the onset and end of moderate and heavy dynamic forearm exercise. Am J Physiol Regul Integr Comp Physiol, 280, 1741-7.

Van Wyk CW, Seedat HA, Phillips VM (1990). Collagen in submucous fibrosis: an electron microscopic study. J Oral Pathol Med, 19, 182-7. 